\title{
PROGRAM AKTIVITAS BERBASIS AEROBIK PADA LANSIA UNTUK MENINGKATKAN KEBUGARAN DAN KUALITAS PROFIL ANTROPOMETRI
}

\author{
Prijo Sudibjo $^{1}$, Suharjana ${ }^{1}$, Krisnanda Dwi Apriyanto ${ }^{1}$ \\ ${ }^{1}$ Ilmu Keolahragaan, Fakultas Ilmu Keolahragaan, Universitas Negeri Yogyakarta, Jl. Colombo No. 1, \\ Karangmalang, Depok, Sleman, Daerah Istimewa Yogyakarta, Indonesia \\ prijo_sudibyo@uny.ac.id, suharjana_fikuny@yahoo.com,krisnandadwia@gmail.com
}

\begin{abstract}
Abstrak
Kegiatan Program Pengabdian kepada Masyarakat ini bertujuan untuk : (1) mendapatkan informasi tentang profil tingkat kebugaran lansia pensiunan Bank Mandiri Yogyakarta, (2) mendapatkan informasi tentang profil tingkat fleksibilitas lansia pensiunan Bank Mandiri Yogyakarta dengan sit and reach test, (3) mendapatkan gambaran antropometri lansia pensiunan Bank Mandiri Yogyakarta yang meliputi berat badan, tinggi badan, IMT, lingkar perut dan lingkar panggul dan (4) memberikan pengetahuan bagi lansia pensiunan Bank Mandiri tentang pentingnya mempertahankan tingkat fleksibilitas dan pentingnya menjaga berat badan ideal. Khalayak sasaran utama dari kegiatan ini adalah Lansia pensiunan Bank Mandiri Yogyakarta yang berjumlah 100 orang. Metode kegiatan PPM dilakukan dengan metode tes pengukuran fleksibilitas dan pelatihan. Pengukuran tes yang dilakukan adalah sit and reach test untuk mengukur tingkat kelentukan/fleksibilitas. Metode pelatihan dilakukan dengan tujuan untuk memberikan gambaran pengetahuan tentang pentingnya melakukan aktivitas fisik utamanya yang bersifat aerobik untuk menjaga kebugaran serta melakukan latihan untuk menjaga tingkat fleksibilitas dan menjaga berat badan ideal bagi lansia pensiunan Bank Mandiri. Pelaksanaan kegiatan PPM ini yang meliputi pengukuran antropometris (pengukuran tinggi badan, berat badan, lingkar perut dan lingkar panggul), cek kesehatan (tekanan darah, denyut nadi), pengukuran kebugaran jasmani dan senam lansia mendapat apresiasi yang baik oleh pihak peserta lansia pensiunan Bank Mandiri Yogyakarta. Dengan adanya kegiatan PPM ini diharapkan para lansia khususnya pensiunan Bank Mandiri Yogyakarta mampu menjaga kesehatan dan melakukan aktivitas fisik sesuai dengan kemampuannya agar kebugaran tetap terjaga.
\end{abstract}

Kata kunci : Pengabdian masyarakat, profil antropometri, kebugaran, lansia

\section{AEROBIC BASED ACTIVITY PROGRAMS IN ELDERLY TO IMPROVE FITNESS AND QUALITY OF ANTHROPOMETRY PROFILE}

\begin{abstract}
This Community Service Program activity aims to: (1) get information about the fitness level profile of elderly Bank Mandiri Yogyakarta retirees, (2) get information about the flexibility level profile of Bank Mandiri Yogyakarta retired elderly people with sit and reach tests, (3) get an anthropometric picture Bank Mandiri Yogyakarta pensioners who cover weight, height, BMI, abdominal circumference and hip circumference and (4) provide knowledge to Bank Mandiri retired elderly people about the importance of maintaining a level of flexibility and the importance of maintaining an ideal body weight. The main target audience for this activity is 100 Mandiri Bank Indonesia pensioners. The method of PPM activities is carried out by the test method of measurement of flexibility and training. Measurement of tests performed is sit and reach test to measure the degree of flexibility/flexibility. The training method is carried out with the aim of providing an overview of knowledge about the importance of performing primarily aerobic physical activities to maintain fitness as well as doing exercises to maintain a level of flexibility and maintain ideal body weight for elderly Bank Mandiri retirees. The implementation of
\end{abstract}


PPM activities which included anthropometric measurements (measurements of height, weight, abdominal circumference and pelvic circumference), health checks (blood pressure, pulse rate), physical fitness measurements and elderly exercise received good appreciation by the elderly participants of Bank Mandiri pensioners Yogyakarta. With this PPM activity it is hoped that the elderly, especially retirees at Bank Mandiri Yogyakarta, will be able to maintain their health and carry out physical activities in accordance with their abilities so that fitness is maintained.

Keywords: Community service, anthropometric profile, fitness, elderly

\section{PENDAHULUAN}

Lansia merupakan satu tahapan yang akan dilalui pada kehidupan manusia. Lansia seharusnya mendapatkan perhatian khusus dari berbagai pihak karena apabila dilihat dari data statistik jumlahnya semakin bertambah. Pada tahun 1990 jumlah lanjut usia 6,3\% (11,3 juta orang), dan tahun 2000 meningkat menjadi 7,6\% (15,2 juta orang). Jumlah lanjut usia di Indonesia pada tahun 2020 diperkirakan akan menempati urutan ke 6 terbanyak di dunia dan melebihi jumlah lanjut usia di Brazil, Meksiko dan negara-negara Eropa (Primana, 2006)

Setiap orang yang melewati masa lansia akan mengalami berbagai perubahan. Perubahan fisik yang terjadi pada lansia diantaranya: kulit keriput, rambut rontok dan berubah putih, volume otot menyusut, ukuran jantung mengecil sehingga kekuatan memompa darah menurun, arteroskerosis, osteoporosis dan juga penurunan tingkat fleksibilitas. Ada beberapa fenomena terkait dengan lansia yang terjadi di sekitar kita. Sebagian lansia tidak dapat menikmati masa tuanya dan malah dianggap sebagai beban bagi keluarga sehingga tidak jarang para lansia dititipkan di panti jompo. Untuk dapat menjadi lansia yang tetap bugar, produktif dan tidak selalu bergantung pada orang lain, maka perlu menerapkan pola hidup sehat. Pola hidup sehat dapat dijalankan dengan cara diantaranya: 1) Berolahraga, 2) Pola makan, 3) Istirahat cukup dan 4) Manajemen stres. Berbagai sumber menyebutkan bahwa dengan berolahraga status kebugaran seseorang dapat ditingkatkan. Aktivitas fisik yang dianjurkan bagi lansia adalah latihan yang sifatnya aerobik, latihan fleksibilitas, latihan kekuatan otot dan keseimbangan. Aktivitas fisik minimal 150 menit setiap minggu dengan intensitas sedang untuk memperoleh kesehatan bagi para lansia (Taylor D, 2014). Seseorang dapat leluasa melakukan olahraga apabila memiliki tingkat fleksibilitas yang baik dan juga bentuk badan yang ideal. Seseorang yang memiliki tingkat fleksibilitas yang rendah dan berat badan yang berlebih akan mengalami masalah ketika melakukan aktivitas. Kita ketahui bahwa dengan melakukan aktivitas fisik/olahraga dengan menggerakkan sebagian besar otot kita maka kebugaran jasmani akan diperoleh. Demikian pula yang terjadi pada lansia, penurunan fungsi fleksibilitas sendi pasti terjadi pada lansia yang akan mempengaruhi pergerakan maksimal sendi.

Kebugaran jasmani merupakan salah satu tolok ukur kesehatan lanjut usia. Kebugaran jasmani yang baik akan meningkatkan daya tahan tubuh terhadap penyakit dan mencegah cedera. Sebaliknya, kebugaran jasmani yang buruk menyebabkan cepat lelah dan sering mendapatkan cedera. Hasil studi pada orang lanjut usia ditemukan sebanyak 4,6\%-8\% mempunyai kekuatan otot kurang, fleksibilitas rendah, tidak mampu menaiki tangga, kesulitan melakukan aktivitas sehari-hari dan kemandirian (U.S. Department of Health and Human Services, 1996)

Penurunan fungsi muskuloskeletal adalah masalah umum yang terjadi pada lansia salah satunya ditandai dengan penurunan fleksibilitas sendi. Penurunan fleksibilitas sendi pada lansia mencapai 40-50\%. Otot-otot yang kuat dan fleksibilitas yang baik merupakan pelindung bagi lanjut usia agar mampu berjalan dengan baik dan mempunyai keseimbangan tubuh yang baik. Agar lansia mempunyai kekuatan otot yang tinggi dan fleksibilitas sendi yang besar, maka komposisi tubuh yang ideal perlu dipertahankan (Cotton \& Ekeroth, 1996). Kebugaran jasmani yang optimal ditunjukkan sebagai kondisi optimal ketahanan kardiorespirasi, kekuatan otot dan 
fleksibilitas, disamping harus tetap mempertahankan berat badan yang ideal (Cotton \& Ekeroth, 1996).

Aktivitas fisik berbasis aerobik berkontribusi pada kebugaran lansia. Tingkat fleksibilitas dan berat badan yang ideal berkontribusi terhadap keleluasaan gerak. Untuk dapat mengetahui tingkat fleksibilitas sendi maka harus dilakukan pengukuran. Tingkat fleksibilitas seseorang dapat diukur dengan melakukan tes sit and reach dengan menggunakan meja ukur yang sudah dilengkapi dengan skala ukur yang berkalibrasi $\mathrm{cm}$. Sedangkan gambaran antropometri dilakukan dengan mengukur tinggi badan, berat badan, indeks masa tubuh (imt), lingkar perut, dan lingkar panggul dengan menggunakan alat ukur berupa stadio meter, timbangan berat badan, serta pita meteran untuk lingkar perut dan panggul.

Tingkat fleksibilitas yang baik dan berat badan yang ideal akan memberikan kemudahan pada setiap manusia untuk menjalani aktivitas hidupnya, demikian pula bagi lansia. Kemudahan untuk menjalani hidup bagi para lansia akan memicu semangat hidup, lebih produktif menjalani hidup dan tidak selalu tergantung pada orang lain. Berdasarkan fakta dilapangan mengenai lansia pensiunan Bank Mandiri Yogyakarta, ditemukan beberapa fakta diantaranya: 1) Para lansia membutuhkan pemahaman tentang aktivias berbasis aerobik untuk menunjang kebugaran. 2) Tingkat fleksibilitas belum diketahui dengan pasti, 3) Pengukuran Antropometri Lansia pensiunan Bank Mandiri belum pernah dilakukan. Berdasarkan kesenjangan masalah tersebut, kami ingin membuat program aktivitas berbasis aerobik pada lansia untuk meningkatkan kebugaran dan kualitas profil antropometris.

\section{Definisi Lansia}

Lansia merupakan tahap akhir perkembangan pada kehidupan manusia. Ada beberapa keadaan yang menandai seseorang masuk pada tahap lansia, diantaranya seseorang gagal untuk mempertahankan kesetimbangan kesehatan dan kondisi stres fisiologisnya. Lansia juga berkaitan dengan penurunan daya kemampuan untuk hidup dan kepekaan secara individual. Usia lanjut juga dapat dikatakan sebagai usia emas karena tidak semua orang dapat mencapai usia lanjut tersebut, maka jika seseorang telah berusia lanjut akan memerlukan tindakan keperawatan yang lebih, baik yang bersifat promotif maupun preventif, agar ia dapat menikmati masa usia emas serta menjadi usia lanjut yang berguna dan bahagia.

Lanjut usia (lansia) merupakan tahap akhir dalam kehidupan manusia. Manusia yang memasuki tahap ini ditandai dengan menurunnya kemampuan kerja tubuh akibat perubahan atau penurunan fungsi organorgan tubuh. Berdasarkan WHO, lansia dibagi menjadi tiga golongan: a. Umur lanjut (elderly): usia 60-75tahun b. Umur tua (old): usia 76-90 tahun c. Umur sangat tua (very old): usia $>90$ tahun.

\section{Perubahan Fisik pada Lansia}

Seseorang yang sudah memasuki usia lanjut, akan mengalami banyak perubahan pada fisik mereka. Beberapa perubahan fisik yang terjadi pada seseorang yang sudah memasuki masa lansia diantaranya: 1) Kulit tubuh dapat menjadi lebih tipis, kering dan tidak elastis lagi; 2) Rambut rontok warnanya berubah menjadi putih, kering dan tidak mengkilat; 3) Jumlah otot berkurang, ukuran mengecil, volume otot secara keseluruhan menyusut dan fungsinya menurun; 4) Otot-otot jantung mengalami perubahan degeneratif, ukuran jantung mengecil, kekuatan memompa darah berkurang; 5) Pembuluh darah mengalami kekakuan; 6) Terjadinya degenerasi selaput lendir dan bulu getar saluran pemapasan, gelembung paru-paru menjadi kurang elastis; 7) Terjadi pengeroposan pada tulang (osteoporosis); 8) Akibat degenerasi di persendian, permukaan tulang rawan menjadi kasar; 9) Karena proses degenerasi maka jumlah nefron (satuan fungsional di ginjal yang bertugas membersihkan darah) menurun. Yang berakibat kemampuan mengeluarkan sisa metabolisme melalui air seni berkurang pula; 10) Proses penuaan dianggap sebagai peristiwa fisiologis yang memang harus dialami oleh semua makluk hidup. 
Kemunduran fungsi organ-organ akibat terjadinya proses penuaan terlihat pada: (1) Kardiovaskuler (Jantung dan pembuluh darah), a) Volume sedenyut menurun hingga menyebabkan terjadinya penurunan isi sekuncup (stroke volume) dan curah jantung (cardiac output); b) Elastisitas`pembuluh darah menurun sehingga menyebabkan terjadinya peningkatan tahanan perifer dan peningkatan tekanan darah; c) Rangsangan simpatis sino atrial node menurun sehingga menyebabkan penurunan denyut jantung maksimal. (2) Respirasi, a) Elastisitas paru-paru menurun sehingga pernafasan harus bekerja lebih keras dan kembang kempis paru tidak maksimal; b) Kapiler paru-paru menurun sehingga ventilasi juga menurun. (3) Otot dan persendian, a) Jumlah motor unit menurun; b) Jumlah mitokondria menurun sehingga akan menurunkan kemampuan otot dan memudahkan terjadinya kelelahan, karena fungsi Mitokondria adalah memproduksi adenosine triphospat (ATP); c) Kekakuan jaringan otot dan persendian meningkat sehingga menyebabkan turunnya stabilitas dan mobilitas. (4) Tulang, mineral tulang menurun sehingga terjadi osteoporosis dan akan meningkatkan resiko patah tulang. (5) Peningkatan lemak tubuh, hal ini menyebabkan gerakan menjadi lamban dan peningkatan resiko terserang penyakit. (6) Kiposis, tinggi badan menjadi menurun.

\section{Penyakit pada Lansia}

Peningkatan usia pada lansia membawa berbagai kompensasi dalam hal penurunan fungsi. Terjadi peningkatan prevalensi penyakit degeneratif pada lansia. Hipertensi merupakan salah satu bentuk penyakit degeneratif yang banyak terjadi pada lansia. Hipertensi dikenal sebagai silent killer karena merupakan faktor kardiovaskuler penting pada lansia. Hipertensi pada lansia beresiko menimbulkan kejadian stroke, penyakit jantung koroner, gagal ginjal dan gagal jantung (Sofia, 2016). Tekanan darah sistolik >160 mmHg menyebabkan kematian 2x lipat akibat berbagai penyebab, kematian akibat kardiovaskuler 3 kali lipat pada wanita dan meningkatkan morbiditas kardiovaskuler 2,5 kali lipat pada kedua jenis kelamin. Bahkan hipertensi stadium I dengan tekanan sistolik 140 - $159 \mathrm{mmHg}$ dan tekanan diastolik < 90 mmHg menyebabkan peningkatan morbiditas dan mortalitas kardiovaskuler secara signifikan.

\section{Jenis Aktivitas Fisik bagi Lansia}

Aktivitas fisik akan memberikan manfaat bagi tubuh apabila dilakukan dengan memenuhi kriteria FITT (frequency, intensity, time, type). Begitu pula bagi lansia, aktivitas fisik yang mereka lakukan juga harus memenuhi kriteria FITT. Frekuensi diartikan sebagai seberapa sering aktivitas fisik dilakukan, berapa hari dalam satu minggu. Intensitas dimaksudkan sebagai seberapa keras suatu aktivitas fisik dilakukan, apakah termasuk dalam intensitas rendah, sedang atau tinggi. Waktu merupakan lamanya aktivitas fisik yang dilakukan dalam satu sesi. Jenis aktivitas fisik yang dilakukan dapat berupa latihan yang sifatnya aerobik maupun anaerobik.

Jenis aktivitas fisik yang sesuai untuk dilakukan bagi lansia meliputi latihan aerobik, penguatan otot, fleksibilitas dan latihan keseimbangan. Banyaknya latihan yang dilakukan tergantung dari tujuan dari setiap individu, apakah untuk kemandirian, kesehatan, kebugaran, atau untuk perbaikan kinerja.

Latihan Aerobik, seseorang yang sudah memasuki masa lanjut usia direkomendasikan untuk melakukan aktivitas fisik setidaknya 30 menit pada intensitas sedang hampir setiap hari dalam seminggu. Melakukan kegiatan dalam aktivitas sehari-hari seperti berjalan, berkebun, melakukan pekerjaan rumah dan naik turun tangga dapat mencapai tujuan yang diinginkan.

Lansia dengan usia lebih dari 65 tahun disarankan melakukan olahraga yang tidak terlalu membebani tulang, seperti berjalan, latihan dalam air, bersepeda statis dan dilakukan dengan cara yang menyenangkan. Bagi lansia yang tidak terlatih harus memulai dengan intensitas rendah dan peningkatan dilakukan secara individual. Berdasarkan toleransi terhadap latihan fisik. 
Olahraga yang bersifat aerobik adalah olahraga yang membuat jantung dan paru bekerja lebih keras untuk memenuhi peningkatan jumlah oksigen, misalnya berjalan, bersepeda, berenang. Latihan dilakukan sekurang-kurangnya 30 menit dengan intensitas sedang.

Latihan Fleksibilitas, Tulang, sendi dan otot saling terkait. Jika sendi tidak dapat digerakkan sesuai dengan Range of Motion (ROM)-nya, maka gerakan sendi menjadi terbatas. ROM yang memadai pada semua bagian tubuh sangat penting untuk mempertahankan fungsi muskuloskeletal, keseimbangan dan kelincahan pada lansia. Latihan fleksibilitas dirancang dengan melibatkan setiap sendi-sendi utama (panggul, punggung, bahu, lutut dan leher).

Fleksibilitas menjadi komponen yang sangat penting bagi setiap manusia untuk dapat menjangkau gerak sendi yang maksimal. Bagi lansia, fleksibilitas menjadi komponen yang sangat penting untuk pembuatan program latihan. Jika suatu sendi tidak digunakan, maka otot yang melintasi sendi akan memendek dan mengurangi ROM. Latihan fleksibilitas dapat meningkatkan kekuatan tendon dan ligament, mempertahankan kekuatan otot yang melintasi sendi, mengurangi nyeri pada kasus osteoarthritis sehingga ROM bisa dipertahankan.

Latihan fleksibilitas disarankan dilakukan pada hari-hari dimana dilakukan latihan aerobik atau 2-3 hari per minggu. Latihan dengan melibatkan peregangan otot dan sendi. Intensitas latihan dilakukan dengan memperhatikan rasa tidak nyaman atau nyeri. Peregangan dilakukan 3-4 kali, untuk masing-masing tarikan dipertahankan 10-30 detik. Peregangan dilakukan utamanya pada kelompok otot-otot besar, dimulai dari otot kecil.

\section{Pengukuran Fleksibilitas}

Fleksibilitas adalah kemampuan gerak maksimal suatu persendian (Sumintarsih, 2007: 29). Kemampuan gerak sendi akan meningkat bila sendi dan otot sering dilatih, kemampuan ini meliputi otot, otot kerangka tubuh, dan sendi. Len Kravitz (2001: 7), kelentukan adalah daerah gerak otot-otot dan persendian tubuh. Meningkatnya kelentukan akan memperbaiki penampilan tubuh dan mengurangi kemungkinan cedera dalam menjangkau setiap gerakan. Fleksibilitas adalah jangkauan gerakan di mana tubuh dapat bergerak (Brian J. Sharkey, 2003: 357). Jangkauan gerak yang dilakukan secara normal adalah jangkuan gerak yang aman untuk dilakukan. Jadi kelentukan adalah kemampuan persendian tubuh yang meliputi elastisitas otot, tendon, ligamen, dan kualitas sendi untuk melakukan jangkauan gerak yang luas.

Pengukuran tingkat fleksibilitas dilakukan dengan menggunakan sit and reach test. Peralatan yang dibutuhkan adalah Bangku, Pengukur/meteran, dan Asisten. Tes Sit and Reach dilakukan sebagai berikut: 1) Orang coba melakukan pemanasan selama 10 menit dan kemudian melepaskan sepatunya; 2) Asisten tersebut mengamankan penggaris ke bagian atas kotak dengan pita sehingga ujung depan kotak berbaris dengan tanda $15 \mathrm{~cm}$ (6 inci) pada penggaris dan ujung nol dari titik penggaris ke arah atlet; 3)Orang coba duduk di lantai dengan kaki terentang penuh dan menyentuh kotak; 4) Atlet menempatkan satu tangan di atas yang lain, perlahan-lahan membungkuk ke depan dan mencapai sepanjang bagian atas penggaris sejauh mungkin, peregangan dilakukan selama dua detik; 5) Asisten mencatat jarak yang ditempuh dengan ujung jari atlet $(\mathrm{cm})$; 6) Orang coba melakukan tes tiga kali

Asisten menghitung dan mencatat rata-rata dari tiga jarak dan menggunakan nilai ini untuk menilai kinerja atlet 


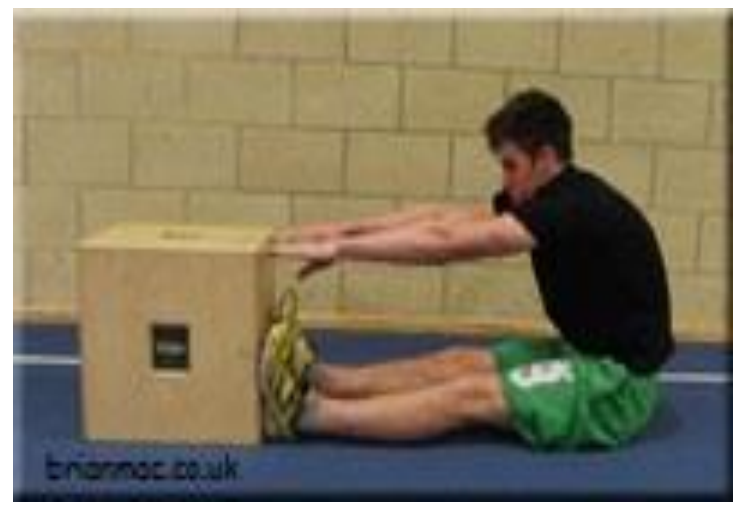

Gambar 1. Pelaksanaan tes sit and reach

Tabel 1. norma pengukuran sit and reach test dibawah ini dapat digunakan untuk seseorang dengan usia 16-19 tahun.

\begin{tabular}{|c|c|c|c|c|c|}
\hline Gender & Excellent & Above average & Average & Below average & Poor \\
\hline Male & $>14$ & $14,0-11,0$ & $10,9-7,0$ & $6,9-4,0$ & $<4$ \\
\hline Female & $>15$ & $15,0-12,0$ & $11,9-7,0$ & $6,9-4,0$ & $<4$ \\
\hline
\end{tabular}

(Davis et al. 2000)

Tabel 2. Nilai normatif sit and reach test untuk lansia pria

\begin{tabular}{|c|c|c|c|}
\hline Age & Below average (inches) & Average (inches) & Above average (inches) \\
\hline $60-64$ & $<-2,5$ & $<-2,5$ to 4,0 & $>4,0$ \\
\hline $65-69$ & $<-3,0$ & $<-3,0$ to 3,0 & $>3,0$ \\
\hline $70-74$ & $<-3,5$ & $<-3,5$ to 2,5 & $>2,5$ \\
\hline $75-79$ & $<-4,0$ & $<-4,0$ to 2,0 & $>2,0$ \\
\hline $80-84$ & $<-5,5$ & $<-5,5$ to 1,5 & $>1,5$ \\
\hline $85-89$ & $<-6,0$ & $<-6,0$ to 0,5 & $>0,5$ \\
\hline $90-94$ & $<-6,5$ & $<-6,5$ to $-0,5$ & $>-0,5$ \\
\hline
\end{tabular}

(Jones \& Ricli, 2002)

Tabel 3. Nilai normatif sit and reach test untuk lansia wanita

\begin{tabular}{|c|c|c|c|}
\hline Age & Below average (inches) & Average (inches) & Above average (inches) \\
\hline $60-64$ & $<-0,5$ & $<-0,5$ to 5,0 & $>5,0$ \\
\hline $65-69$ & $<-0,5$ & $<-0,5$ to 4,5 & $>4,5$ \\
\hline $70-74$ & $<-1,0$ & $<-1,0$ to 4,0 & $>4,0$ \\
\hline $75-79$ & $<-1,5$ & $<-1,5$ to 3,5 & $>3,5$ \\
\hline $80-84$ & $<-2,0$ & $<-2,0$ to 3,0 & $>3,0$ \\
\hline $85-89$ & $<-2,5$ & $<-2,5$ to 2,5 & $>2,5$ \\
\hline $90-94$ & $<-4,5$ & $<-4,5$ to 1,0 & $>1,0$ \\
\hline
\end{tabular}

(Jones \& Ricli, 2002)

\section{Pengukuran Antropometri}

Antropometri berasal dari bahasa Yuani yiaitu antropos (tubuh) dan metros (ukuran), jadi antropometri diartikan sebagai ukuran tubuh. Antropometri gizi berhubungan dengan berbagai macam pengukuran dimensi tubuh dan komposisi tubuh dari berbagai tingkat umur dan tingkat gizi. Antropometri ini sangat umum digunakan untuk mengukur status gizi dari berbagai ketidakseimbangan antara asupan protein dan energi. Gangguan ini biasanya terlihat dari pola pertumbuhan fisik dan proporsi jaringan tubuh, seperti lemak, otot dan jumlah air dalam tubuh (Depkes, 2007). 
Khusus pada penilaian status gizi lansia, yang diukur dengan menggunakan metode antropometri adalah sebagai berikut:

(1) Berat badan, berat badan merupakan gambaran massa jaringan termasuk cairan tubuh. Pengukuran berat badan ini paling sering digunakan untuk berbagai kelompok usia karena pengukuran berat badan ini juga dapat digunakan sebagai indicator status gizi pada saat skrining gizi dilakukan. Hal ini disebabkan karena berat badan sangat sensitive terhadap berbagai perubahan komposisi tubuh, sehingga penurunan atau kenaikan berat badan ini berkaitan erat dengan komposisi tubuh. Beberapa pertimbangan mengapa berat badan paling sering digunakan sebagai indikator penialian status gizi, diantaranya: a) Parameter yang paling baik, mudah terlihat perubahan dalam waktu singkat karena perubahan-perubahan konsumsi makanan dan kesehatan; b) Memberikan gambaran status gizi sekarang; c) Merupakan ukuran antropometri yang sudah dipakai secara umum dan luas di Indonesia; d) Ketelitian pengukuran tidak banyak dipengaruhi oleh keterampilan pengukur.

(2) Tinggi badan, tinggi badan merupakan hasil pertumbuhan kumulatif sejak lahir sehingga parameter ini dapat memberikan gambaran mengenai riwayat status gizi masa lalu. Tinggi badan ini diukur dengan menggunakan alat ukur dengan menggunakan alat pengukuran seperti microtoise dengan ketepatan $1 \mathrm{~cm}$ tetapi bisa juga dengan alat pengukuran non elastik ataupun metal.

(3) Indeks Massa Tubuh (IMT), Indeks massa tubuh (IMT) digunakan sebagai parameter dari seseorang terkait dengan berat badan, yang merupakan perbandingan antara berat badan dalam kilogram dengan tinggi badan dalam meter kuadrat (Fox, 1998). Hubungan antara IMT dan persentase lemak kurang lebih sama, meskipun terdapat perbedaan digunakan jika IMT lebih dari 30 maka seseorang dikatakan obesitas. Obesitas dapat diartikan sebagai kelebihan lemak tubuh (Guyton, 2006). Penanda kandungan lemak tubuh yang digunakan adalah IMT. Indeks Massa tubuh bukan merupakan suatu pengukuran langsung terhadap adipositas dan tidak dapat dipakai pada individu yang mempunyai IMT tinggi akibat besarnya masssa otot (Guyton, 2006), cara yang paling baik untuk mendefinisikan obesitas adalah dengan mengukur persentase lemak tubuh total. Meskipun persentase lemak tubuh dapat diperkirakan dengan berbagai cara, seperti pengukuran tebal lipatan kulit, impedansi bioelektrik ataupun pengukuran berat badan di dalam air. Namun, Indeks massa tubuh lah yang paling sering digunakan untuk menentukan obesitas (Guyton, 2006).

Indeks massa tubuh digunakan untuk menentukan status gizi orang dewasa berusia 18 tahun atau lebih. Indeks massa tubuh memiliki kelebihan, yaitu pengukuran sederhana (mudah dilakukan) dan dapat digunakan untuk menentukan berat badan ideal seseorang. Namun, penilaian dengan IMT juga memiliki beberapa kelemahan, diantaranya 1) hanya dapat digunakan untuk menentukan status gizi seseorang yang berusia 18 tahun ke atas, 2) tidak dapat diterapkan pada bayi, remaja, ibu hamil dan olahragawan, 3) tidak dapat digunakan untuk menentukan status gizi seseorang yang menderita sakit edema, asites dan hepatomegali (Djoko Pekik Irianto, 2007).

Indeks massa tubuh (IMT) adalah ukuran yang saat ini digunakan untuk menentukan antropometri tinggi atau berat badan orang dewasa dan untuk mengklasifikasikan ke dalam norma kelompok yang sudah ditetapkan (Frank \& Nuttall, 2015). Penafsiran yang umum tentang indeks massa tubuh adalah merupakan indeks dari seseorang yang mengalami kegemukan. IMT juga digunakan sebagai faktor risiko untuk pengembangan beberapa masalah kesehatan. Selain itu, sudah banyak digunakan dalam menentukan kebijakan kesehatan masyarakat. IMT sangat bermanfaat dalam berbagai studi dengan mendefinisikan secara spesifk kaitan antara IMT dengan masalah kesehatan. Namun, IMT bukanlah indikator yang paling baik untuk menentukan persen lemak tubuh (Frank \& Nuttall, 2015). IMT juga tidak bisa memberikan informasi tekait massa lemak yang terkadung dalam setiap anggota tubuh yang berbeda. 
Badan kesehatan dunia telah menggolongkan kategori indeks massa tubuh menjadi 4 golongan, yaitu: kurus, normal, kelebihan berat badan dan obesitas. Seseorang individu akan dikategorikan menjadi kurus apabila IMT berada pada kisaran 15-19,9, berat badan dikategorikan normal jika IMT berada pada angka 20-24,9, kelebihan berat badan jika IMT adalah 25-29,9, dan obesitas jika IMT berada pada angka 30-35.

Tabel 4 . Klasifikasi Indeks Massa Tubuh

\begin{tabular}{|c|c|c|}
\hline No. & Status Gizi & Indeks Massa Tubuh \\
\hline 1. & Kurus & $15-19,9$ \\
\hline 2. & Normal & $20-24,9$ \\
\hline 3. & Kelebihan Berat Badan & $25-29,9$ \\
\hline 4. & Obesitas & $30-35$ \\
\hline
\end{tabular}

(4) Lingkar Perut, Pengukuran lingkar perut dilakukan untuk mengetahui ada tidaknya obesitas abdominal/sentral. Jenis obesitas ini sangat berpengaruh terhadap kejadian penyakit kardiovaskular dan diabetes melitus, yang akhir-akhir ini juga erat hubungannya dengan kejadian sindroma metabolik. Obesitas didefinisikan sebagai kelebihan kandungan lemak di jaringan adiposa. Batas untuk obesitas umumnya adalah kelebihan berat lebih dari $20 \%$ berat standar normal. Menurut World Health Organization (WHO) obesitas merupakan akumulasi jaringan lemak yang berlebihan atau abnormal yang dapat menyebabkan gangguan kesehatan. Obesitas sentral merupakan keadaan kelebihan jaringan adiposit yang terkumpul pada daerah abdomen (intraabdominal fat), dapat ditentukan melalui pengukuran lingkar perut dengan hasil positif pria lebih dari $90 \mathrm{~cm}$ dan wanita lebih dari $80 \mathrm{~cm}$.

Penentuan obesitas sentral dilakukan dengan pengukuran lingkar perut dengan menggunakan pita pengukur yang tidak meregang. Pengukuran dilakukan di pertengahan antara batas tulang rusuk yang dapat teraba dengan bagian atas krista iliaka. Sampel diperiksa dalam keadaan berdiri dengan tangan di samping dan posisi kaki saling menutup. Sampel diminta untuk santai sebelum pengukuran dan mengambil nafas dalam, bernafas seperti biasa sebelum pengukuran dilakukan dan diukur saat fase ekspirasi normal. Hasil pengumpulan lingkar perut kemudian dikelompokkan kedalam dua kelompok lingkar perut obesitas sentral $(\geq 90 \mathrm{~cm})$ dan lingkar perut normal $(<90 \mathrm{~cm})$.

(5) Lingkar Panggul, lingkar panggul adalah indikator untuk menentukan obesitas abdominal yang diperoleh melalui hasil pengukuran panjang lingkar yang diukur pada lingkar maksimal dari pantat dan pada bagian atas simpysis ossis pubis. Lingkar panggul yang besar (tanpa menilai IMT dan lingkar pinggang) memiliki risiko diabetes melitus dan penyakit kardiovaskular yang lebih rendah (Seidell et al., 2001).

Cara melakukan pengukuran lingkar panggul: a) Responden mengenakan pakaian yang tidak terlaku menekan; b) Responden berdiri tegak dengan kedua lengan berada pada kedua sisi tubuh dan kaki rapat; c) Pengukur jongkok di samping responden sehingga tingkat maksimal dari penggul terlihat; d) Alat pengukur dilingkarkan secara horizontal tanpa menekan kulit. Seorang pembantu diperlukan untuk meletakkan alat ukur dengan tepat; e) Dibaca dengan teliti hasil pengukuran pada pita hingga $0,1 \mathrm{~cm}$ terdekat.

\section{Manfaat Olahraga bagi Lansia}

Perubahan pada sistem kardiovaskular ditandai dengan adanya perubahan anatomi di jantung dan peredaran darah, menurunnya denyut nadi maksimal, meningkatnya tekanan darah, hipotensi postural, perubahan dalam pemulihan denyut nadi sesudah aktivitas fisik, menurunnya jumlah darah yang dipompa dalam tiap denyutan, dan perubahan dalam sel darah (sel darahmerah, hemoglobin). Olahraga disebutkan dapat menurunkan tekanan darah pada hipertensi, meningkatkan stroke volume (jumlah darah yang dikeluarkan jantung dalam satu kali denyutan), meningkatkan produksi sel darah merah, menurunkan LDL dan menaikkan 
HDL serta mempercepat pemulihan setelah aktivitas fisik. Badan kesehatan dunia telah merekomendasikan aktivitas fisik minimal 150 menit setiap minggu dengan intensitas sedang untuk memperoleh kesehatan bagi para lansia (Taylor D, 2014).

\section{METODE}

Khalayak sasaran utama dari kegiatan ini adalah Lansia pensiunan Bank Mandiri Yogyakarta yang berjumlah 100 orang. Kegiatan ini terdiri dari bebrapa metode yaitu: 1) Ceramah, Metode ini dipilih untuk menyampaikan teori atau penjelasan tentang pentingnya menjaga kesehatan dan menjaga kebugaran khususnya bagi lansia pensiunan Bank Mandiri. Teori yang diberikan meliputi: perubahan fisiologis pada lansia, penyakit pada lansia, jenis aktivitas fisik yang sesuai bagi lansia; 2) Diskusi, Diskusi dilakukan untuk mengetahui keadaan yang sebenarnya terjadi pada lansia yang meliputi kesehatan dan kebugaran. Diskusi ini bertujuan agar lansia mendapatkan informasi dan pengetahuan tentang menjaga kesehatan dan kebugaran terkait dengan materi PPM; 3) Praktek, kegiatan praktek yang dilakukan meliputi tes kebugaran dengan jalan cepat atau jogging pada lingkasan yang sudah disediakan dengan durasi waktu 6 menit kemudian dicatat jarak tempuhnya. Sebelum dilakukan tes kebugaran, para lansia harus menjalani serangkaian tes kesehatan dan pengukuran antropometri yang meliputi: tinggi badan, berat badan, tekanan darah, nadi, fleksibilitas. Selain jalan cepat atau jogging, juga dilakukan senam bagi lansia. Hal ini bertujuan agar lansia mengetahui jenis gerakan yang aman dilakukan, mengingat semakin tua maka semakin menurun fungsi fisiologis tubuh.

\section{HASIL PENELITIAN}

Berikut data deskriptif hasil pengukuran komponen-komponen kebugaran jasmani disajikan pada table di bawah ini:

Tabel 5. Data Deskriptif Hasil Pengukuran Komponen-Komponen Kebugaran Jasmani

\begin{tabular}{|c|c|c|c|}
\hline No. & Data & Jumlah lansia (n) & Rata-rata \\
\hline $\mathbf{1 .}$ & Umur (tahun) & 79 & 64,92 \\
\hline $\mathbf{2 .}$ & Berat Badan $(\mathrm{kg})$ & 73 & 66,76 \\
\hline $\mathbf{3 .}$ & Tinggi Badan $(\mathrm{cm})$ & 73 & 159,53 \\
\hline $\mathbf{4 .}$ & Keseimbangan & 74 & 4,68 \\
\hline $\mathbf{5 .}$ & Lingkar Perut (cm) & 73 & 90,85 \\
\hline $\mathbf{6 .}$ & Lingkar Panggul (cm) & 73 & 101,73 \\
\hline $\mathbf{7 .}$ & Fleksibilitas (cm) & 66 & 23,79 \\
\hline $\mathbf{8 .}$ & Jalan cepat 6 menit (meter) & 64 & 528,83 \\
\hline
\end{tabular}

Tabel 6. Rata-rata Usia Lansia berdasarkan Jenis Kelamin

\begin{tabular}{|c|c|c|}
\hline Jenis Kelamin & Jumlah lansia (n) & Rata-rata (tahun) \\
\hline Laki-laki & 36 & 67,33 \\
\hline Wanita & 43 & 64,47 \\
\hline Jumlah & 79 & \\
\hline
\end{tabular}

Tabel 7. Rata-rata Berat Badan Lansia berdasarkan Jenis Kelamin

\begin{tabular}{|c|c|c|}
\hline Jenis Kelamin & Jumlah lansia (n) & Rata-rata (kg) \\
\hline Laki-laki & 35 & 68,54 \\
\hline Wanita & 38 & 65,12 \\
\hline Jumlah & 73 & \\
\hline
\end{tabular}


MEDIKORA, Vol. XVII No. 2 Oktober 2018 - 154

Prijo Sudibjo, Suharjana, Krisnanda Dwi Apriyanto

Tabel 8. Rata-rata Tinggi Badan Lansia berdasarkan Jenis Kelamin

\begin{tabular}{|l|c|c|}
\hline \multicolumn{1}{|c|}{ Jenis Kelamin } & Jumlah lansia (n) & Rata-rata (cm) \\
\hline Laki-laki & 35 & 164,34 \\
\hline Wanita & 38 & 155,1 \\
\hline Jumlah & 73 & \\
\hline
\end{tabular}

Tabel 9. Rata-rata Keseimbangan Lansia berdasarkan Jenis Kelamin

\begin{tabular}{|l|c|c|c|}
\hline \multicolumn{1}{|c|}{ Jenis Kelamin } & Jumlah lansia (n) & Rata-rata (detik) & Keterangan \\
\hline Laki-laki & 33 & 4,77 & \\
\hline Wanita & 41 & 4,61 & \\
\hline Jumlah & 74 & & \\
\hline
\end{tabular}

Tabel 10. Rata-rata Lingkar Perut Lansia berdasarkan Jenis Kelamin

\begin{tabular}{|l|c|c|c|}
\hline \multicolumn{1}{|c|}{ Jenis Kelamin } & Jumlah lansia (n) & Rata-rata $(\mathbf{c m})$ & Keterangan \\
\hline Laki-laki & 34 & 93,65 & Obesitas \\
\hline Wanita & 39 & 88,48 & Obesitas \\
\hline Jumlah & 73 & & \\
\hline
\end{tabular}

Hasil pengumpulan data lingkar perut dapat dikelompokkan ke dalam dua kelompok yaitu lingkar perut obesitas sentral dan lingkar perut normal. Pada laki-laki norma lingkar perut obesitas sentral $(\geq 90 \mathrm{~cm})$ dan lingkar perut normal $(<90 \mathrm{~cm})$. Sedangkan pada wanita norma lingkar perut obesitas sentral $(\geq 80 \mathrm{~cm})$ dan lingkar perut normal $(<80 \mathrm{~cm})$. Maka dapat disimpulkan baik pada lansia laki-laki maupun wanita memiliki lingkar perut yang obesitas.

Tabel 11. Rata-rata Lingkar Panggul Lansia berdasarkan Jenis Kelamin

\begin{tabular}{|c|c|c|c|}
\hline Jenis Kelamin & Jumlah lansia (n) & Rata-rata (cm) & Keterangan \\
\hline Laki-laki & 34 & 100,53 & \\
\hline Wanita & 39 & 102,78 & \\
\hline Jumlah & 73 & & \\
\hline
\end{tabular}

Tabel 12. Rata-rata Fleksibilitas Lansia berdasarkan Jenis Kelamin

\begin{tabular}{|c|c|c|c|}
\hline Jenis Kelamin & Jumlah lansia (n) & Rata-rata (cm) & Keterangan \\
\hline Laki-laki & 31 & 23,49 & baik \\
\hline Wanita & 35 & 24,05 & baik \\
\hline Jumlah & 66 & & \\
\hline
\end{tabular}

Lansia laki-laki rata-rata mempunyai nilai fleksibilitas $23,49 \mathrm{~cm}(9,25$ inci) dengan usia rata-rata lansia laki-laki adalah 68,54 tahun. Lansia laki-laki dikatakan memiliki tingkat fleksibilitas yang baik apabila memiliki nilai > 3 inci $(7,62 \mathrm{~cm})$. Nilai rata-rata fleksibilitas pada lansia laki-laki adalah 23,49 $\mathrm{cm}$ maka dapat dikatakan memiliki fleksibilitas yang baik.

Lansia wanita rata-rata mempunyai nilai fleksibilitas $24,05 \mathrm{~cm}(9,5$ inci) dengan usia ratarata lansia laki-laki adalah 64,47 tahun. Lansia wanita dikatakan memiliki tingkat fleksibilitas yang baik apabila memiliki nilai $>4,5$ inci $(11,43 \mathrm{~cm})$. Nilai rata-rata fleksibilitas pada lansia laki-laki adalah 24,05 $\mathrm{cm}$ maka dapat dikatakan memiliki fleksibilitas yang baik.

Tabel 13. Rata-rata Jarak Tempuh Jalan Cepat 6 menit Lansia berdasarkan Jenis Kelamin

\begin{tabular}{|c|c|c|c|}
\hline Jenis Kelamin & Jumlah lansia (n) & Rata-rata (m) & Keterangan \\
\hline Laki-laki & 30 & 541 & Normal \\
\hline Wanita & 34 & 518 & Normal \\
\hline Jumlah & 64 & & \\
\hline
\end{tabular}


Usia rata-rata lansia laki-laki adalah 68,54 tahun. Apabila dilihat tabel norma untuk aktivitas jalan selama 6 menit, lansia laki-laki dikatakan memiliki norma yang normal apabila mampu menempuh jarak sejauh 560-700 yard (512-640 meter). Maka lansia laki-laki memiliki rata-rata kebugaran yang normal, karena lansia rata-rata mampu menempuh jarak 541 meter selama 6 menit.

Usia rata-rata lansia wanita adalah 64,47 tahun. Apabila dilihat tabel norma untuk aktivitas jalan selama 6 menit, lansia wanita dikatakan memiliki norma yang normal apabila mampu menempuh jarak sejauh 500-635 yard (457-580 meter). Maka lansia wanita memiliki rata-rata kebugaran yang normal, karena lansia rata-rata mampu menempuh jarak 518 meter selama 6 menit.

\section{HASIL DAN PEMBAHASAN}

Pelaksanaan kegiatan pengabdian pada masyarakat ini mendapatkan apresiasi yang baik oleh pihak pengurus paguyuban lansia ataupun peserta lansia pensiunan Bank Mandiri. Dikatakan demikian karena sebagian besat peserta, baru pertama kali menjalankan tes kebugaran khusus lansia, yang sebelumnya hanya tes kesehatan saja yang dilakukan. Kegiatan ini memberikan pengalaman baru bagi peserta. Selain itu peserta juga mengetahui hal-hal yang terkait dengan pengukuran antropometris mereka dan pengukuran kebugaran jasmani lansia. Hasil dari semua pengukuran disampaikan kepada lansia.

Dari total keseluruhan lansia sejumlah 100 orang, hanya 79 yang hadir pada kegiatan PPM yang diselenggarakan. Dari sejumlah 79 lansia yang hadir, tidak semua lansia mengikuti seluruh rangkaian tes pengukuran yang diadakan. Hal tersebut terjadi karena ada beberapa lansia yang datang terlambat dan ada beberapa lansia yang tidak bersedia untuk mengikuti sebagian dari seluruh rangkaian tes pengukuran yang diselenggarakan.

\section{KESIMPULAN}

Pelaksanaan kegiatan pengabdian pada masyarakat ini mendapatkan apresiasi yang baik oleh pihak pengurus paguyuban lansia ataupun peserta lansia pensiunan Bank Mandiri. Dikatakan demikian karena sebagian besat peserta, baru pertama kali menjalankan tes kebugaran khusus lansia, yang sebelumnya hanya tes kesehatan saja yang dilakukan. Kegiatan ini memberikan pengalaman baru bagi peserta. Selain itu peserta juga mengetahui hal-hal yang terkait dengan pengukuran antropometris mereka dan pengukuran kebugaran jasmani lansia. Hasil dari semua pengukuran disampaikan kepada lansia.

Dari total keseluruhan lansia sejumlah 100 orang, hanya 79 yang hadir pada kegiatan PPM yang diselenggarakan. Dari sejumlah 79 lansia yang hadir, tidak semua lansia mengikuti seluruh rangkaian tes pengukuran yang diadakan. Hal tersebut terjadi karena ada beberapa lansia yang datang terlambat dan ada beberapa lansia yang tidak bersedia untuk mengikuti sebagian dari seluruh rangkaian tes pengukuran yang diselenggarakan.

\section{DAFTAR PUSTAKA}

Al-Mamani A, et al. 2009. Atherosclerosis and Physical Activity. Review Article. Oman Medical Journal, Volume 24, Isssue 3, July 2009.

Brian J. Sharkey. (2003). Kebugaran dan Kesehatan. Penerjemah: Eri Desmarini Nasution. Jakarta: PT. RajaGrafindo Persada.

C.Z. Pandjaitan. 1991. Tetap Bugar Sampai Tua. Indonesia Publishing House offset

Cotton RT, Ekeroth CJ.Personal trainer manual, the resource for professionals. San Diego; American Council on Exercise. 1996; 21-27

Davis, B. et al. (2000) Physical Education and the study of sport, 4th ed. London: Harcourt Publishers.

Departemen Kesehatan. (2007). Riset kesehatan dasar (pedoman pengukuran antropometri), diakses pada tanggal 1 September 2011, <http://www.litbang.depkes.go.id>. 
Djoko Pekik Irianto. 2007. Panduan Gizi Lengkap Keluarga dan Olahragawan. Yogyakarta: CV Andi Offset.

Fox El, Bowers R.W \& Foss ML. 1998. The Pysiological Basis of Physical Education and Athletics (4th Ed.). Philadelphia: Saunders College.

Guyton, A. C., dan Hall, J.E. 2006. Fisiologi Kedokteran. (Terjemahan). Jakarta: Penerbit Buku Kedokteran EGC.

Jones C.J., Rikli R.E., Measuring functional fitness of older adults, The Journal on Active Aging, March April 2002, pp. 24-30.

Len Kravitz. (2001). Panduan Lengkap: Bugar Total. Jakarta: PT. RajaGrafindo Persada.

Primana, Dadang Arief. Fleksibilitas Sendi Wanita Lanjut Usia pada Berbagai Komposisi Tubuh. JKM. Vol. 6, No. 1, Juli 2006

Seidell JC, Molarius A, van der Kuip D, Hofman A, Witteman JC. Visscher TL. A comparison of body mass index, waist-hip ratio and waist circumference as predictors of all-cause mortality among the elderly: the Rotterdam study. Int J Obes Relat Metab Disord. 2001 Nov;25(11):1730-5.

Sofia Rhosma Dewi. 2016. Spiritualitas dan persepsi kesehatan lansia dengan hipertensi di wilayah kerja puskesmas mayang jember. The Indonesian Journal of Health Science, vol. 6, no. 2, juni 2016, 229

Sumintarsih. (2007). Kebugaran Jasmani untuk Lanjut Usia. Olahraga. Vol. 13,

Taylor Denise, 2014. Review: Physical activity is medicine for older adults. Postgrad Med J 2014; 90:26-32. Th. XIII, No. 1. Hlm. 26-40.

U.S. Department of Health and Human Services, Physical Activity and Health A Report the Surgeon General, Atlanta, GA: U.S Department of and Human Services, Centers for Disease Control and Prevention, National Center for Chronic Disease Prevention and Health Promotion. 1996

WHO, Report of a WHO Scientific Group. The epidemiology of aging, the uses of epidemiology in the study of the elderly. Technical Report Series. 1984; 706: 7-84. 